Research Report of the Institute of Business Informatics

Editors: Prof. Dr. J. Becker, Prof. Dr. H. L. Grob, Prof. Dr. K. Kurbel, Prof. Dr. U. Müller-Funk, Prof. Dr. R. Unland, Prof. Dr. G. Vossen

Working Paper No. 39

\title{
Cooperative Knowledge Processing: The Key Technology for Future Organizations
}

Stefan Kirn

University of Münster, Institute of Business Informatics

Grevener Str. 91, D-48159 Münster, Germany, Tel. (0251) 83-9750, Fax (0251) 83-9754

July 1995 


\section{Contents}

1 Introduction

2 Organizational Paradigms: Evolving Role of Information Technology 5

2.1 Early Work

2.2 Decision-Oriented Organization Theory 6

2.3 Management of the 1990's Research Program 7

2.4 Organizational Integration of Human and Machine-Based Problem Solving $\quad 10$

3 New Organizational Strategies: A Brief Review 10

3.1 Business Process Orientation 11

3.2 Fractalization 12

3.3 Fractalization versus Business Process Orientation: Conflicting Strategies? 12

4 Redesigning Business Processes: Towards A Model of Computerized Organizations 14

$\begin{array}{ll}4.1 \text { Requirements } & 14\end{array}$

4.2 Basic Organizational Model 15

4.3 The Strategic, Tactical, and Operative Layer of Process Management 17

5 Cooperative Knowledge Processing 18

$\begin{array}{ll}5.1 \text { Overview } & 18\end{array}$

5.2 Multi-Agent Decision Support Systems (MA-DSS) 20

5.3 Human Computer Cooperative Work 22

6 Organizational Applications 24

6.1 Attention Focusing Capabilities $\quad 24$

6.2 Knowledge Discovery 25

6.3 Business Process Orientation 26

$\begin{array}{ll}6.3 .1 \text { Overview } & 26\end{array}$

6.3.2 Customization of Processes $\quad 27$

6.3.3 Coordination of Interacting Organizational Processes 29

6.4 Self Organization Skills 30

7 Summary 31

8 References 33 


\begin{abstract}
Drawing from the challenges organizations are faced with today, there is a growing understanding that future market success, and long-term survival of enterprises will increasingly be related to the effectiveness of information technology utilization. This, however, requires to intertwine much more seriously organizational theory and research in information processing as it has been done before.

Within this paper, we approached this aim from the perspective of radically decentralized, computerized enterprises. We further assume that organizations are increasingly processoriented, rather than applying to structuring organizations based on task decomposition and assignment. This scenario reveals that, due to the inherent autonomy of organizational units, the coordination of decentralized organizational activities (workflows, processes) necessitates a cooperative style of problem solving. On this basis, the paper introduces into the research area of cooperative knowledge processing, with a particular focus on multi-agent decision support systems, and human computer cooperative work. Finally, several important organizational applications of cooperative knowledge processing are presented that demonstrate how future enterprises can take great advantage from these new technologies.
\end{abstract}




\section{Introduction}

Global competition, dynamic markets, and rapidly decreasing cycles of technological innovations provide important challenges for organizations today. Worldwide (just in time) availability of information, and permanent changes in their cultural, social, and political settings require enterprises to dramatically improve their flexibility, and their self organization capabilities. Two main organizational strategies have been developed, by which enterprises do address these challenges today: radical decentralization of hierarchical structures, and customer orientation through enterprise-wide business process (re-)engineering.

Both strategies, decentralization and business process orientation, apply to an organizational model that is increasingly penetrated through modern information technologies. More and more, organizational activities are going to be implemented by computational entities instead of involving human employees, and organizational processes perform increasingly on a pure computational basis. It has further been argued that modern information technologies cause organizational disintegration. This has given rise to the idea of computerized, informationintegrated enterprises as the model of future organizations.

Decentralization enforces the autonomy of organizational subunits. As a consequence, local decision procedures as well as the behavior of those organizational subunits turn out to be under decentralized control. This calls for a bottom up approach to coordination. On the other hand, business process orientation requires a more centralized approach, or at least a global view from which a top down approach to business process (re-)engineering can be developed. As a result, any approach resolving the conflict between these two organizational strategies requires to sustain the autonomy of the organizational units involved. This, in turn, calls for a pluralistic, cooperative, knowledge-based approach to coordination and conflict resolution.

Drawing from these requirements - computerization, fractalization, process orientation the paper argues that Cooperative Knowledge Processing is a key technology for computerized, process-driven organizations. For this purpose, we first review how the role of information technology in organization theory has changed in the past. Then, we study fractalization, and business process orientation in order to work out the inherent conflict that exists between these strategies. Next, we present an agent-oriented approach to business process orientation, together with a basic model of computerized organizations. We then introduce into the approach, and subfields, of cooperative knowledge processing. On this basis, some applications of cooperative knowledge processing in business, organization, and management are presented. Finally, the last section summarizes the results of the paper. 


\section{Organizational Paradigms: Evolving Role of Information Technology}

Organizational design requires to shape organizational structures so that the resulting body can pursue the aims and objectives formally introduced, negotiated and decided upon by the owners of the organization, its members and participants. Thus, the description, analysis, and explanation of organizations is one of the most important areas in management science. Since long, a diversity of organizational models has been developed, each with a particular focus, and with distinct applicability to theoretical and real-world problems. Out of these, we have selected four models in order to demonstrate how the integration of information technology into organizational research has changed over the past 50 to 70 years. They are: (1) the black box model originating from traditional macroeconomis, (2) the production-oriented organizational model of Gutenberg, (3) the decision-oriented approach to modeling organizations, and (4) the organizational model originating from the Management of the 1990's Research Program which has been conducted by the Massachusetts Institute of Technology (MIT). While the first two models introduce the historical roots, models (3) and (4) originate from contemporary organizational research that considers information technology a constitutive component of modern organizations.

\subsection{Early Work}

The black box-model emerged from traditional macroeconomics; it considers organizations single atomic entities. This model is not concerned with why an organization behaves as it does, nor does it relate internal structures and activities of an enterprise to its success on the market. Thus, there is no need and even no means to investigate how organizational information processing should be operated in order to improve the behavior of an enterprise, or to contribute to the integration of the organization with its environment.

The production-oriented model has been developed as a part of Gutenberg's production theory (Gutenberg, 1951). Gutenberg distinguished two subsystems of an enterprise, namely the physical subsystem (that is, the physical place of production) and the administrative subsystem that involves decision making, planning, organization, and the management of information. In that view, enterprises have an organization. Organization is the tool by which the results of planning can be set in place. The important contribution of Gutenberg was to reveal that the internal organizational structure affects the outcome of production. However, his model involves two important shortcomings: production workers are considered as machine-like components of manufacturing systems, a concept that draws from the theory of scientific management (Taylor, 1919). Further, the model does not investigate how the management and processing of information can actively contribute to organizational aims and objectives. 


\subsection{Decision-Oriented Organization Theory}

The next important step in organization theory turned the focus of interest to decision making. It had been recognized that any economic activity presupposes decision making which, in turn, requires extensive information processing capabilities (March and Simon, 1958; Huber and McDaniel, 1986). By this way, the human factor and models of decision making have been introduced into the organizational model. As a result, three distinct organizational subsystems have been identified that together constitute the decision-oriented organizational model. They are:

1. The subsystem of organizational aims and objectives integrates the aims and objectives of the persons, groups, and organizational bodies that are related to the organization.

2. The information processing subsystem stores, retrieves, and processes data, information and knowledge in order to enable decisions that fit with the organizational aims and objectives. The information processing subsystem may, or may not involve information processing technology.

3. In general, decision making involves more than one person. Thus, the result of decision making also depends upon the social subsystem of an organization, e.g. the social relationships, the balance of power, the availability of information, etc.

Together, these three subsystems constitute organizations as goal-driven socio-technical entities that acquire and process information. Enterprises are organizations involving humans who collaborate in order to produce commodities and services. The effectiveness of organizational processes depends directly upon the capability of decision making. Information technology adds to decision making in that it speeds up decision processes, and in that it improves the quality of decisions by involving more actual, and even more relevant information as before. In that view, information technology is a tool that facilitates the storage, accessibility, maintenance, and manipulation of data. Software systems are assumed to being more or less passive technical components that are not capable to apply to organizational roles. Thus, the decisionoriented approach may involve quite similar shortcomings than the production-oriented model, which considered the organization being a tool to implement decisions, and which involved a far too restrictive model of production workers. 


\subsection{Management of the 1990's Research Program}

The Management of the 1990's program was charged with the task of investigating the impact of the new information technologies on organizations in order to find out how the organizations of the 1990's — and beyond — will differ from those of today (Thurow, 1991). To this purpose, the program used a very broad definition of information technology including all types of hardware, communication networks, and software. It also addressed the impact of rapidly increasing availability of computing power, and the growing importance of information technology integration.

From our perspective, four implications from this research are particularly relevant (Morton, 1991, p. 11-21):

1. Information technology is enabling fundamental changes in the way work is done.

The degree to which a person can be affected by changes in information technology depends on how much of the work is based on information. Morton writes that information technology will be able to radically change cost structures - production work, coordinative work, and management work - of at least 50 per cent of the members of an organization. Information technology will affect the economics and functionality of the coordination process in three ways:

a) Distance can be shrunk to zero. Thus, the location of work can be re-examined, as can potential partners.

b) Time can be shrunk toward zero or, at least, be significantly reduced.

c) The accessibility and, thus, the role of organizational memory will change radi cally, as will the definition and maintenance of organizational knowledge.

2. Information technology causes a disintegration of traditional organizational forms.

The Management of the 1990's research program "... has shown that information technology is a critical enabler of the re-creation (redefinition) of the organization" (Morton, 1991, p. 17). It affects the distribution of power, function, and control, the definition of organizational aims and objectives, and organizational culture. In that view, information technology facilitates adhocracies, organizational networking, the creation of virtual enterprises, and other new forms of getting work more effectively done as it is possible today. In such organizational settings, horizontal and vertical structures can be created and modified within 
and across organizational borders, just depending on the current task, the availability of resources, and the actual situation on world-wide markets.

3. Information technology is enabling the integration of business functions at all levels within and between organizations.

Due to the continuing expansion of electronic networks and their integration into global networks, the ability to flexibly interconnect tasks and people is increasingly available and affordable. Recent successes of standardization efforts in information technology enable companies to easily exchange tasks, and even to exchange capabilities within and across enterprises. This enables enterprises to electronically integrate their structures and processes in four different forms: within the value chain, by creating end-to-end links between value chains of different organizations, through value chain substitution via subcontract or alliance, and through electronic markets. Thus, the relevance of the membership-criteria will dramatically be reduced, intra- and interorganizational structures will be intertwined, and organizational boundaries will become more permeable as they are today. In consequence, organizational strategies will no longer be defined in isolation within single organizational units only (Figure 1).

However, one should note that organizations must have the right information technology infrastructure, e.g. communication networks, application programs, interconnecting software, and educated and empowered users before they can fully exploit any of these four forms of electronic integration. 


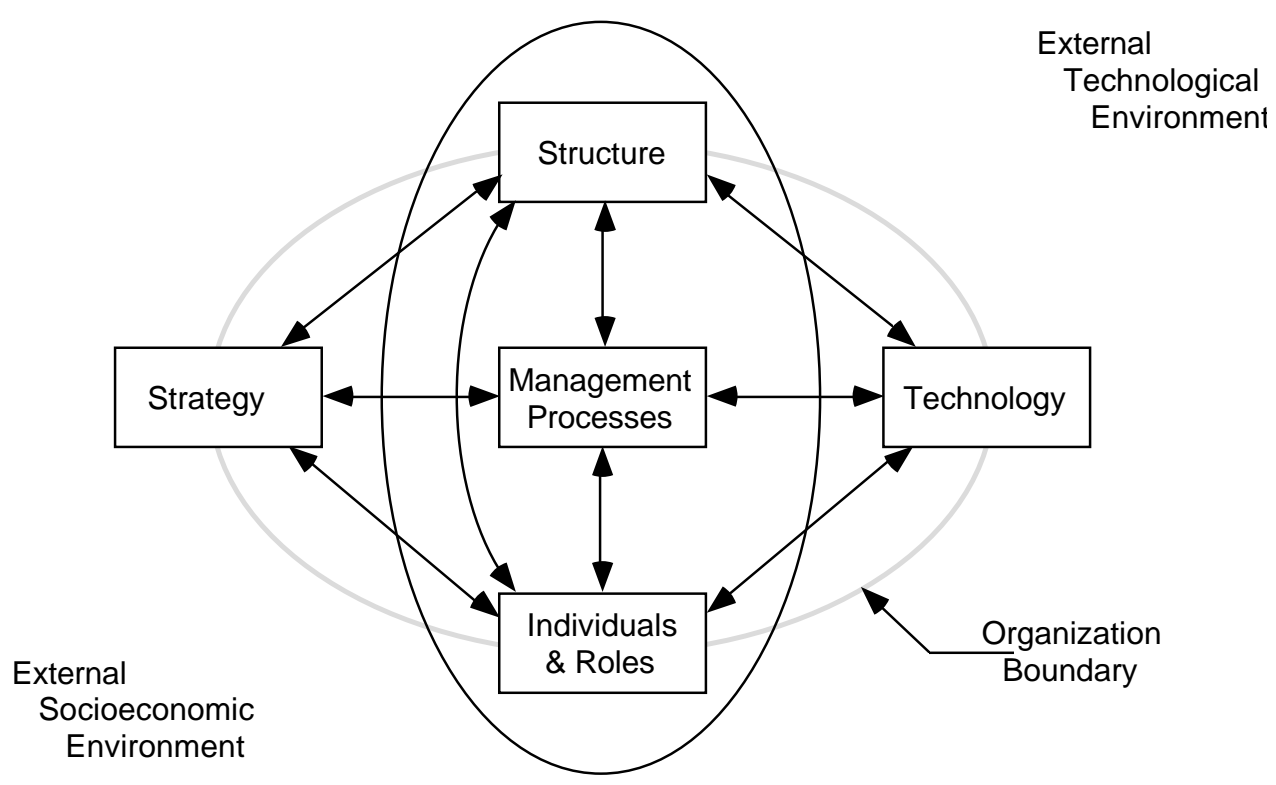

Figure 1: Framework of the Management of the 1990's Program (Morton, 1991)

4. Information technology presents new strategic opportunities for organizations that reassess their missions and operations.

According to Morton, the shifting competitive climate together with new ways getting work done and the increased electronic integration requires organizations to step back and rethink their missions and the way they are going to conduct their operations. Here, two major stages need to be considered. Within the automate stage information technology applications are designed to take the cost out of "production" (Morton, 1991, p. 16). Automation often generates new information as a by-product. This involves the informate stage (Zuboff, 1988). Its distinguished characteristic is that this new sort of information can require the persons concerned, to change their skills and management practices if this new information is to be used successfully in order to improve the performance of an organization. In other words: the "doer", or machine minder will become an "analyzer" who understands the overall process rather than just looking at the local task (Morton, 1991, p. 17).

From the Management of the 1990's program we learn that computer technology does not only provide an infrastructure for communication and data management, but that it enables the implementation of new organizational strategies, and that it even initiates the development of completely new organizational solutions. This has already changed the internal structures of many existing enterprises, and has resulted in major modifications of worldwide market relationships (Morton, 1991), too. 


\subsection{Organizational Integration of Human and Machine-Based Problem Solving}

The above discussion reveals that information technology is more and more penetrating our models, and our understanding of organizations. This requires us to rethink the organizational approach. In future, we will see an increasing number of organizations that turn out to be pure computational entities collaborating in virtual environments in order to make monies for their owners (e.g., Levitt et.al., 1994; de Greef, 1994; Bocionek, 1994). Such computational organizations have emerged recently in the financial services industry, where a significant portion of today's business at the capital markets is already operated by self-contained trading agents.

It thus has been recognized that it is quite unsatisfying to study such artificial enterprises from a traditional organization theory perspective (Kirn et.al., 1994; Carley \& Prietula, 1994). The only link left to traditional organization theory is that of humans are the owners of such computational organizations. The methods and tools provided by traditional organization theory are not suitable to deal with such computational organizations. Therefore, organization theory needs to be extended in that it can also be involved into describing, analyzing, explaining, and designing computerized, information integrated enterprises of the future. This raises the problem of how autonomous, self-contained computational agents (and, accordingly, computational organizations) can be incorporated into the organizational model.

These issues have been addressed by research in the recently emerged discipline of computational organization theory (e.g., Masuch, 1990; Carley \& Prietula, 1994; special issue of this journal in December 1993). Further work has been conducted in related disciplines such as operations research (Matsuda, 1992), computer supported cooperative work (Steiner et.al., 1990), coordination theory (Malone and Crowston, 1993; Kirn, 1994; Kirn and O'Hare, 1995)

\section{New Organizational Strategies: A Brief Review}

In the past, a great deal of work has been devoted to develop new strategies by which organizations can meet the challenges of dynamic, and sometimes even unpredictable environments, rapidly decreasing cycles of innovation, and worldwide competition. Two different strategies can be identified: re-engineering the processes of an organization, and radical decentralization (fractalization) of the structure of organizations. However, current approaches of business process orientation are, at least partially, incompatible with the strategy of radical decentralization. Applying to the Management of the 1990's research program we suggest to resolve this inherent conflict through modern information technologies. 


\subsection{Business Process Orientation}

According to Davenport a process may be defined as a structured, measured set of activities designed to produce a well-specified output for a single customer or market. Process orientation puts strong emphasis on how work is getting done, in contrast to a more product-oriented focus on what. Thus, business process orientation represents a revolutionary change in perspective: it turns the organization on its head, or at least on its side (Davenport, 1993, p. 5).

The structure of business processes can clearly be distinguished from the more hierarchical forms of structure within an organization. While the latter is typically a snapshot that shows how responsibilities, resources, communication channels, and information flow are distributed across an organization, the former provides a dynamic view of how the organization delivers value. Further, while structures cannot be assessed or improved directly, processes involve cost, time, output quality and customer satisfaction, they relate to well-known triggering events and they result in well-defined final states. Thus, whenever one reduces cost or increases customer satisfaction processes are improved, and not the organizational hierarchy.

The key issues of process orientation can be summarized in five points (Davenport, 1993, pp. 299-303):

1. Processes are the key elements to be addressed in order to transform organizations and to improve their performance.

2. An explicit - and holistic - approach to process orientation is necessary. This involves the description and analysis as well as the formal representation and the information technology-based management of business processes as the key factors for success.

3. Information technology provides a powerful tool for enabling and implementing processes.

4. How an enterprise approaches organization and human resources is critical to the enablement and implementation of smart business processes.

5. Process orientation must occur within a strategic context and must be guided by a vision of the future process states.

Since the pioneering work of Porter (Porter, 1985), business process orientation has received an overwhelming attention by both academia and practitioners (Scheer, 1994). Its most important contribution is that it provides for a systematic, intelligible approach to the modeling and (re-)engineering of organizations. Thus, for the rest of the paper we assume that the design of 
future organizations will focus on processes. That is, we will primarily be concerned with the modeling, management, and control of processes rather than applying to task decomposition, and to the modeling of static organizational structures.

\subsection{Fractalization}

The enterprise of the future will be radically decentralized, in order to meet the challenges of the increasing complexity of their environment, and the dynamics of world-wide competition. Decentralization involves the allocation of autonomy, resources, and responsibilities to deeper levels of the organizational hierarchy (Tapscott and Caston, 1993; Warnecke, 1991). This requires enterprises to replace the traditional approach of hierarchical planning by more decentralized concepts of coordination. In turn, autonomous organizational subunits need to exhibit a much greater degree of intelligence and self-referencing skills than they do today. This has given rise to the notion of organizational fractals (Warnecke, 1991). These are equipped with self-organization skills thus enabling them not only to recursively form complex, highly organized entities but also to modify these entities, for instance with respect to dynamic environments or changing customer demands. Organizational fractals are provided with operational definitions of their local goals, and are capable to cooperatively creating global hierarchies of aims and objectives. They exhibit intelligent local and global coordination skills, and a benevolent style of cooperation. Accordingly, fractalization permits large organizations to exhibit greater flexibility and adaptivity, and it also provides to them a medium through which they can effectively refresh their learning capabilities (Warnecke, 1991).

\subsection{Fractalization versus Business Process Orientation: Conflicting Strategies?}

Organizational fractals involve a maximum degree of local autonomy, self-control, and selforganization skills. Aiming to maximize their local utility (for instance, in terms of profit), organizational fractals decide on their own whether they are willing to cooperate, or to collaborate with other organizational units. There is no direct means, even not for the top management of an enterprise, by which fractals can be compelled to behave in a certain manner. The single acceptable way to control their behavior is through designing a globally consistent system of aims and objectives (Warnecke, 1991).

However, due to bounded rationality, organizations are not able in most cases to establish consistent goal hierarchies. Instead, the different goals that exist within an organization are more or less inconsistent, the knowledge about goals and relationships between them remains 
necessarily incomplete, uncertain, fuzzy, and sometimes even false. Additional goal conflicts may arise between the goals of an organization and the preferences of its customers, between different organizations that wish to cooperate, and between the customers of distinct organizations that wish to pursue their aims in close cooperation.

On the other hand, current approaches to business process orientation presuppose that organizations have the time, knowledge and skills to precisely describe, analyze, and design enterprise-wide business processes. They further suppose that, through an iterative (not necessarily algorithmic) procedure of refinement, these descriptions can be augmented, or instantiated to more detailed descriptions of (partial) processes and fully expanded specifications of the respective workflows. This requires a centralized approach to business process engineering, or, at least, a global perspective (Hammer and Champy, 1991) which, by definition, cannot exist within fractalized enterprises. Instead, organizational fractals must cooperate whenever they aim to create (bottom up!) an enterprise-wide business process. A similar conflict exists between the local autonomy of organizational fractals, and the need to tie them to an existing business process. These conflicts are directly related to the degree of autonomy of the fractals involved.

As a consequence, it is very difficult or may be even impossible in general to resolve these conflicts by standardized rules and decision criteria. Whenever one aims to introduce business process orientation into a system of organizational fractals one needs to apply to decentralized, cooperation-based concepts of process modeling and control (Kirn et.al., 1994). Any coordination concept must sustain the individual autonomy of each single fractal, and it must provide appropriate knowledge processing techniques in order to cope with the epistemological issues of incompleteness, uncertainty, and fuzziness.

These challenges can be addressed by recent advances in cooperative knowledge processing technology (Warnecke, 1991; Kirn et.al., 1994). This work aims to integrate decentralized but autonomously operating data and knowledge sources, and it involves standard techniques from Artificial Intelligence in order to cope with the epistemological issues mentioned above. These techniques can help to bridge boundaries within and across organizations, and to flexibly exchange tasks, know how, and geographically distributed resources between distinct organizational units (Hastings, 1993). By this way, they are quite well suited to re-integrate disintegrated organizational structures that have been replaced through "electronic" arm's-length relationships (Morton, 1991; Hastings, 1993). 


\section{Redesigning Business Processes: Towards A Model of Computerized Organizations}

\subsection{Requirements}

The above discussion demonstrates that to resolve the conflict between decentralization and process orientation requires us to rethink the conceptual approach of modeling processes. The basic assumptions on which such work should be built are:

1. No longer do organizations involve human members only. Instead, future organizations will also comprise artificial, software-based members on their own right. We thus adopt an agent-oriented approach to modeling organizations, that is, an agent represents either a human or an artificial, software-based member of an organization.

2. In contrast to traditional organization theory, members of an organization are regarded as script-providers who are able to autonomously operate more or less complex scripts. This affects the modeling of processes, which, now, is primarily concerned with customization of processes, rather than with creating them from scratch (Kirn et.al., 1994).

3. The distinction between members of an organization and entire organizational units is becoming more permeable: In one case a single agent may provide an appropriate script to solve a problem, while in another situation the same task may be tackled by a cooperative process, for instance created and operated by an adhocracy that involves agents from two or more organizational units.

4. In the past, organizational structures have been created top down, thus representing fundamental decisions about the division of labor across an organization. A quite similar approach has been employed in business process orientation, where global processes are transformed into subprocesses, workflows, and activities. However, process design in decentralized organizational settings needs to put much more emphasis on the bottom up perspective. Drawing from the capabilities of humans, computational agents, and organizational fractals the task of designing organizations will primarily be concerned with creating workflows and processes bottom up.

Though, still much more important, the bottom up approach to business process engineering enables organizations to gain strategic advantages by improving their capability to create new products based upon already available capabilities, by applying their competencies much more 
efficiently to the market than before, and, thus, by significantly improving their responsiveness to dynamic market environments.

\subsection{Basic Organizational Model}

Referring to the requirements described above, our organizational model grounds on interacting organizational processes that perform within an arbitrary organizational structure. This approach focuses on process modeling and control, rather than dealing with the description and design of organizational hierarchies. Thus, the organizational structure may be a functional hierarchy, an adhocracy, a strategic partnership, or anything else. We also note that this perspective excludes some issues that are important in organization theory in general (e.g. organizational behavior, interactions between organizations and their environment, etc.), but, for the moment, it facilitates concentrating on process modeling, management, and control.

The organizational structure builds on four different types of agents: (single) agents (informal) social groups - (formal) organizational units - enterprise. On this basis, (at least) four different organizational layers can be identified (Figure 2). Additional layers can easily be introduced, e.g. if organizational units (recursively) include one or more other organizational units. Within Figure 2 the enterprise can be viewed as an embodiment of a hierarchy and inter-agent activities.

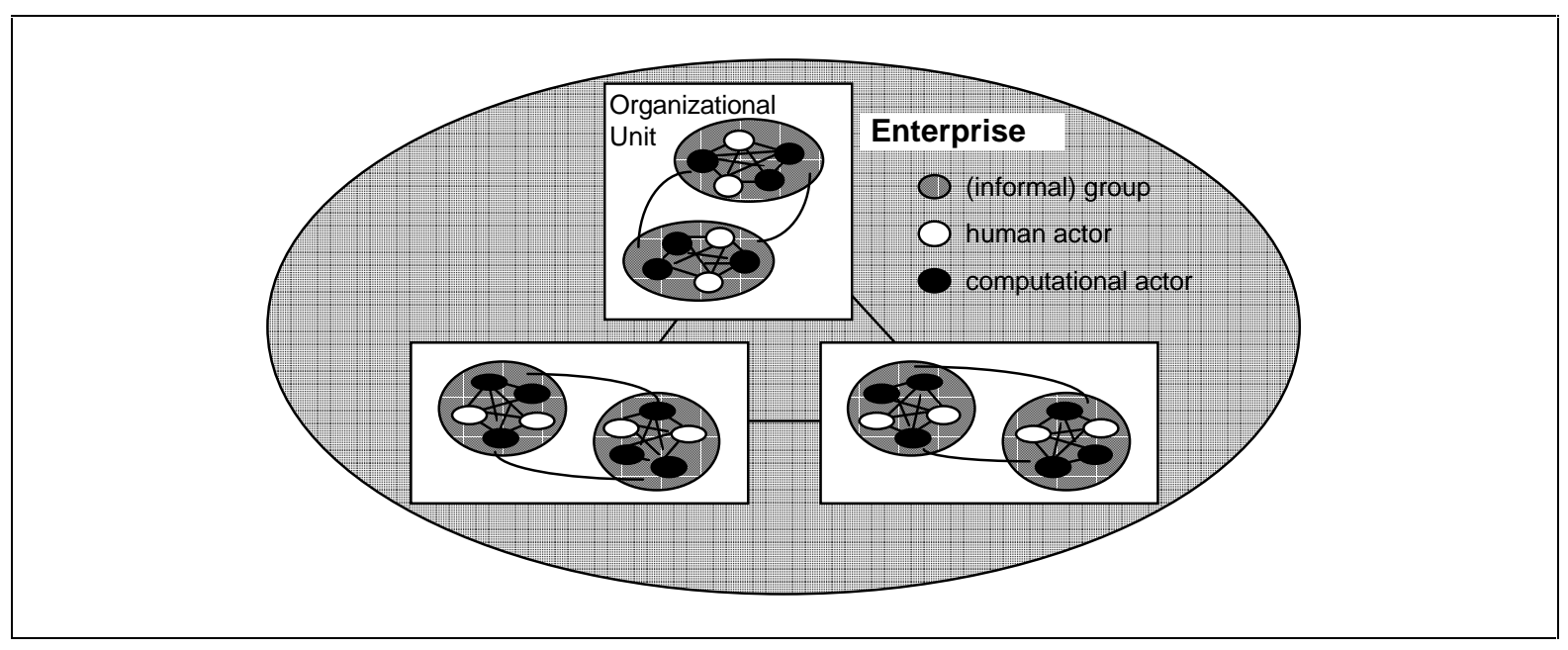

Figure 2: Symbolic Representation of a 4-Layered Organization

We now turn our interest to the modeling of organizational processes. Four distinct types of processes can be identified which refer to the four organizational layers mentioned above: 
1. (Individual) scripts: Sequences of atomic operations performed by one individual agent. That is, human and computational agents are script providers. We assume that agents primarily contribute complex scripts instead of performing atomic activities only.

2. Workflows: Networks of individual scripts on the level of groups thus involving the work of at least two individual agents. From the perspective of the organization groups are "workflow providers".

3. Processes: Networks of workflows (thus involving the work of one or more groups) and scripts (thus involving the work of one or more individual agents) on the level of a single organizational unit, which are assumed to be organizational fractals. They are "process providers". We further assume that any process represents exactly one single product or service being provided by one single organizational fractal (Figure 3).

4. Business processes: Refer to enterprise-wide networks of processes, which involve at least two organizational units working in close collaboration. Business processes are implementing value chains. They are the tool through which customer orientation can be implemented across whole organizations.

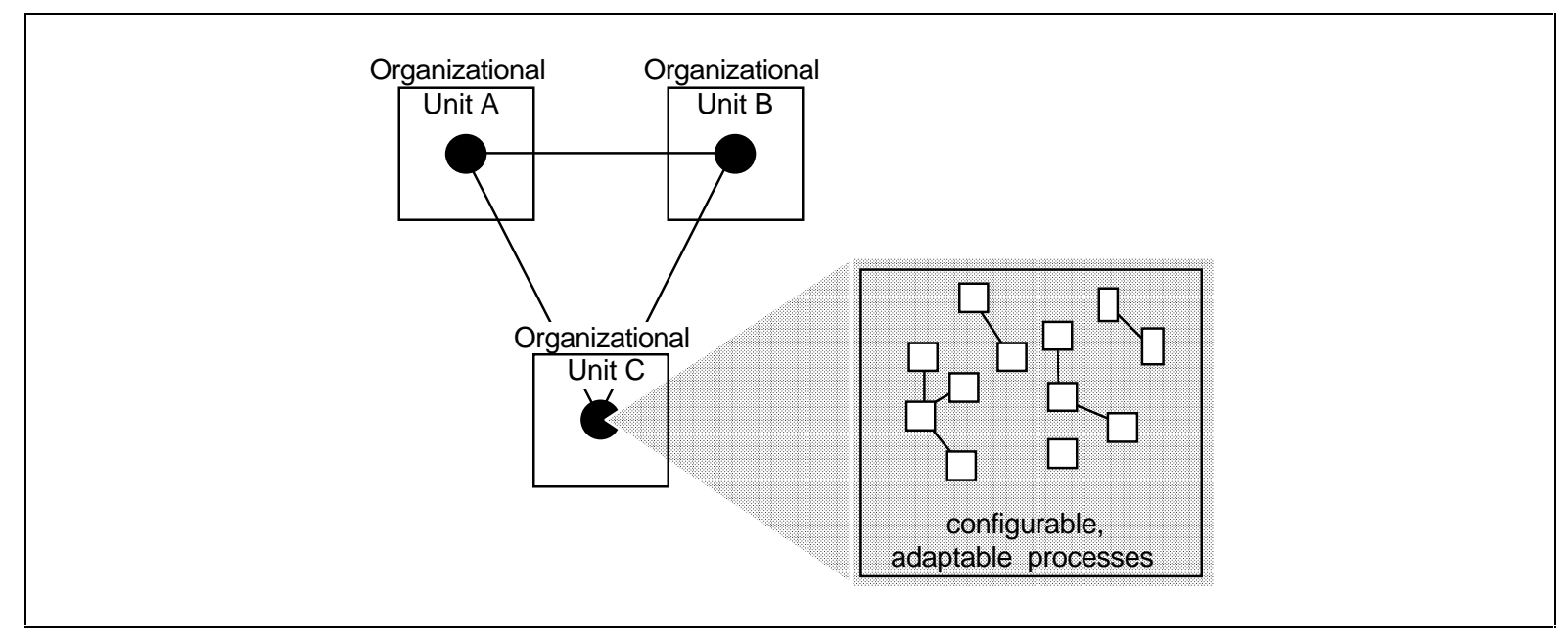

Figure 3: Cooperating Organizational Units 


\subsection{The Strategic, Tactical, and Operative Layer of Process Management}

The definitions introduced above reveal that processes must be modelled on different levels of abstraction. For instance, scripts represent very detailed information about single (atomic) activities, while, in general, representations of business processes need not to be operational at all.

In order to identify the appropriate levels of abstraction we apply to the discrimination into strategic, tactical, and operative management. On the strategic layer, we are concerned with lean management, business process (re-)engineering, and process innovation (Davenport, 1993). That is, the focus of strategic management is on business processes, in order to implement full customer orientation across the whole enterprise. Important tasks involve the redesign of value chains, total quality management, process-oriented cost management, and, if necessary, outsourcing of processes. On the tactical layer, management is concerned with the modeling, analysis, and reorganization of processes. One of the most important issues here is to raise the flexibility of organizations. This is particular important in the services industry, where a direct relationship exists between a supplier's ability to meet the preferences of individual customers, and its success on the market. Finally, on the operative layer we are concerned with the modeling, analysis, implementation, and control of (parameterized) workflows. This task can be supported by workflow management systems that are well suited to create and maintain formal representations of workflows, and to trigger and control the operation of wellorganized, distributed activities.

Scripts, and workflows are part of the operative layer of an organization, processes refer to the tactical layer, and business processes belong to the strategic layer of an enterprise. Thus, whenever we are concerned with workflow management we refer to the operative layer. In general, conventional software concepts are well suited to instantiate workflows according to the requirements of a particular organizational situation. Moving to the tactical layer we learn that knowledge-based techniques are required in order to create configurations of processes, to cope with uncertainty and incomplete knowledge, and to resolve goal conflicts that may arise between different organizational units cooperating together, or between an organization and its customers. In other words: workflow management provides for automation rather than supporting organizational flexibility, while process management primarily concentrates on the flexibility of organizations rather than addressing the automation of processes. 


\section{Cooperative Knowledge Processing}

\subsection{Overview}

Modern information technologies cause a disintegration of enterprises, which requires us to turn the attention to the (re-)integration of previously distributed organizational knowledge. This task requires a collaborative, interdisciplinary effort of different scientific disciplines, as there are traditional and computational organization theory, computer supported cooperative work, human computer interaction, and information processing technology (Simoudis and Adler, 1992). With respect to such work, Figure 4 depicts some important topics in cooperative knowledge processing research. These are addressed by several ambitious research programs, for instance within ESPRIT (Europe), the Intelligent Manufacturing Systems initiative (Japan), and the DARPA Knowledge Sharing Effort (United States).

We have argued, that, due to the inherent autonomy of organizational units any approach to coordinate decentralized activities supposes a cooperative style of problem solving. For this purpose, and with respect to the number of humans and computational agents, six distinct types of cooperation can be identified. Each cooperation type refers to a distinguished area of research in cooperative knowledge processing (Table 1).

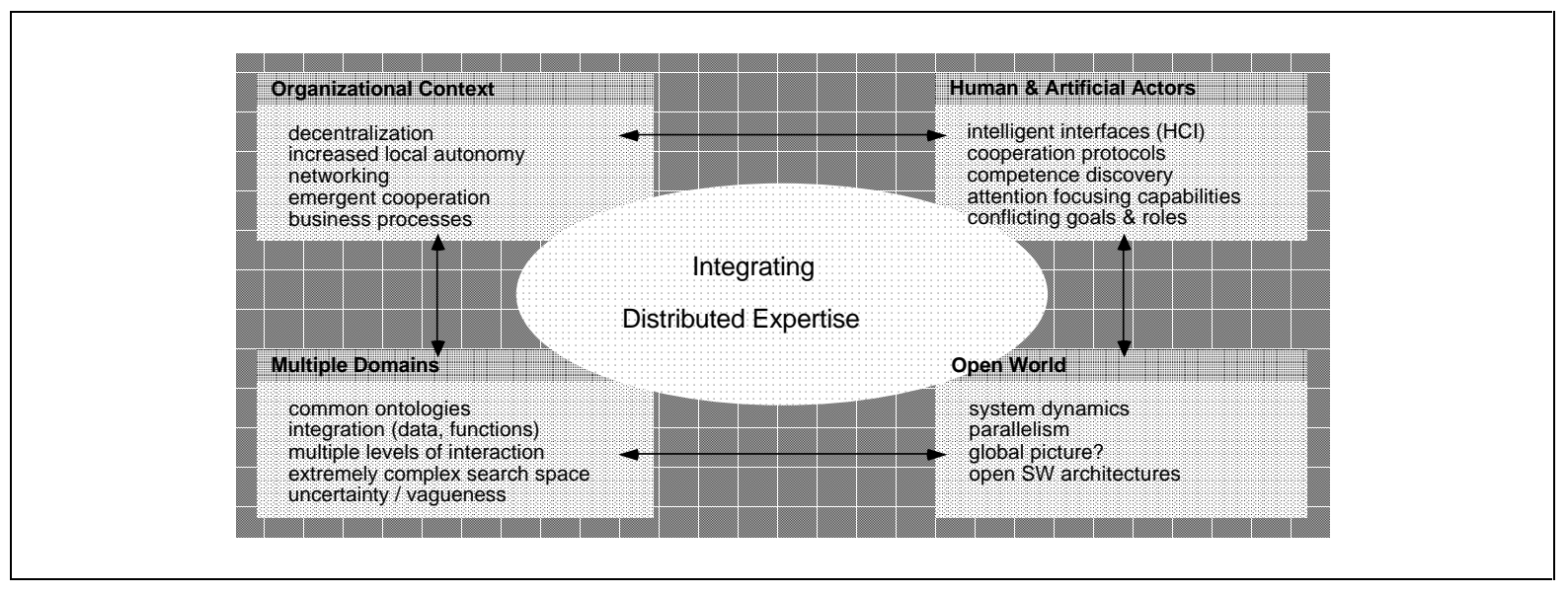

Figure 4: The Challenges of Cooperative Knowledge Processing 


\begin{tabular}{|l|c|c|c|}
\hline $\begin{array}{l}\text { multiple computational } \\
\text { agents }\end{array}$ & $\begin{array}{c}\text { Distributed Artificial } \\
\text { Intelligence }\end{array}$ & $\begin{array}{c}\text { Multi-Agent Decision } \\
\text { Support Systems }\end{array}$ & $\begin{array}{c}\text { Human Computer } \\
\text { Cooperative Work }\end{array}$ \\
\hline \multirow{2}{*}{ one computational agent } & $\begin{array}{c}\text { Personal Assistants } \\
\text { (Assisting Computers, } \\
\text { User Agents) }\end{array}$ & Groupware \\
\hline $\begin{array}{l}\text { no computational agent } \\
\text { involved }\end{array}$ & & & traditional \\
\cline { 2 - 4 } & & Organization Theory \\
\hline
\end{tabular}

Table 1: Taxonomy of Cooperation Types in Computerized Organizations

As far as knowledge processing is concerned, traditional organization theory and groupware address cooperation between humans. Thus, they both are concerned with supporting cooperative knowledge processing, but they do not provide any cooperative knowledge processing technology. Recent work in computational organization theory is concerned with applying agent-oriented techniques to implementing, modeling and simulation of organizational structures and processes (Carley \& Prietula, 1994; Masuch 1990). Research in personal assistants (Hoschka, 1991; Bocionek, 1994) aims to develop hardware platforms and software agents in order to discharge humans from routine work. This has given rise to develop concepts of cooperation between one human expert and its intelligent assistant (Stolze, 1991). Distributed artificial intelligence, on the other hand, is concerned with cooperative knowledge processing among pure computational entities, thus excluding humans from being involved (Bond and Gasser, 1988). Multi-agent decision support systems, and human computer cooperative work (Steiner et.al., 1990; Kirn, 1993) refer to cooperation scenarios where a group of software agents either collaborate with one, or with several humans. Research in these areas involves perspectives from distributed artificial intelligence, (intelligent) personal assistants, organization theory, and social sciences.

Within this paper, we are mainly interested in those subfields of cooperative knowledge processing, that involve two or more software agents, and at least one human expert. We further suppose that cooperation takes place in an organizational context. That is, the members of such human computer teams are supposed to join the same organizational body, for instance the same company, organizational network, or virtual enterprise. We thus concentrate on multi-agent decision support systems and human computer cooperative work, being primarily interested in the theoretical foundations, and organizational applications of these areas of cooperative knowledge processing. 


\subsection{Multi-Agent Decision Support Systems (MA-DSS)}

Up to now, multi-agent decision support systems are assumed being a subfield of distributed artificial intelligence (Bond and Gasser, 1988). However, this classification is far too restrictive if one applies to decision making in organizations, because of three reasons:

1. Main Research Interest: The main interest in doing research in multi-agent decision support systems is on decision support. Thus, research in multi-agent decision support systems addresses the integration of distributed expertise through information processing technology, in order to improve human decision making.

2. Research Perspectives: Research in multi-agent decision support systems involves three distinct research perspectives:

a) The decision support perspective aims to improve (human) decision making through the integration of distributed expertise while at the same time preserving the local autonomy of "expertise-providers".

b) The organizational perspective assumes that decision making is performed in organizations. Thus, any research approach is required to involve organizational structures and processes, hierarchies of aims and objectives, organizational behavior, etc.

c) The technology perspective supposes information technology support for cooperative knowledge processing. This involves a strong distributed artificial intelligence perspective, supplemented through advanced human computer interaction technology.

d) Thus, multi-agent decision support systems have three main roots those of decision theory, organization theory, and distributed artificial intelligence. Further, the development of multi-agent decision support systems requires to involve deep knowledge from the respective application domains (for instance, financial consulting).

3. Enabling Technology: The design of attention (and, subsequently, knowledge) focusing capabilities of an organization is one of the hardest problems in organization theory in general (Blanning et.al., 1992). From that perspective, distributed artificial intelligence is an important enabling technology. However, it has been argued that distributed artificial intelligence remains to be adapted more closely to the requirements of cooperation, and coordination in (human) organizations (Kirn, 1994). 


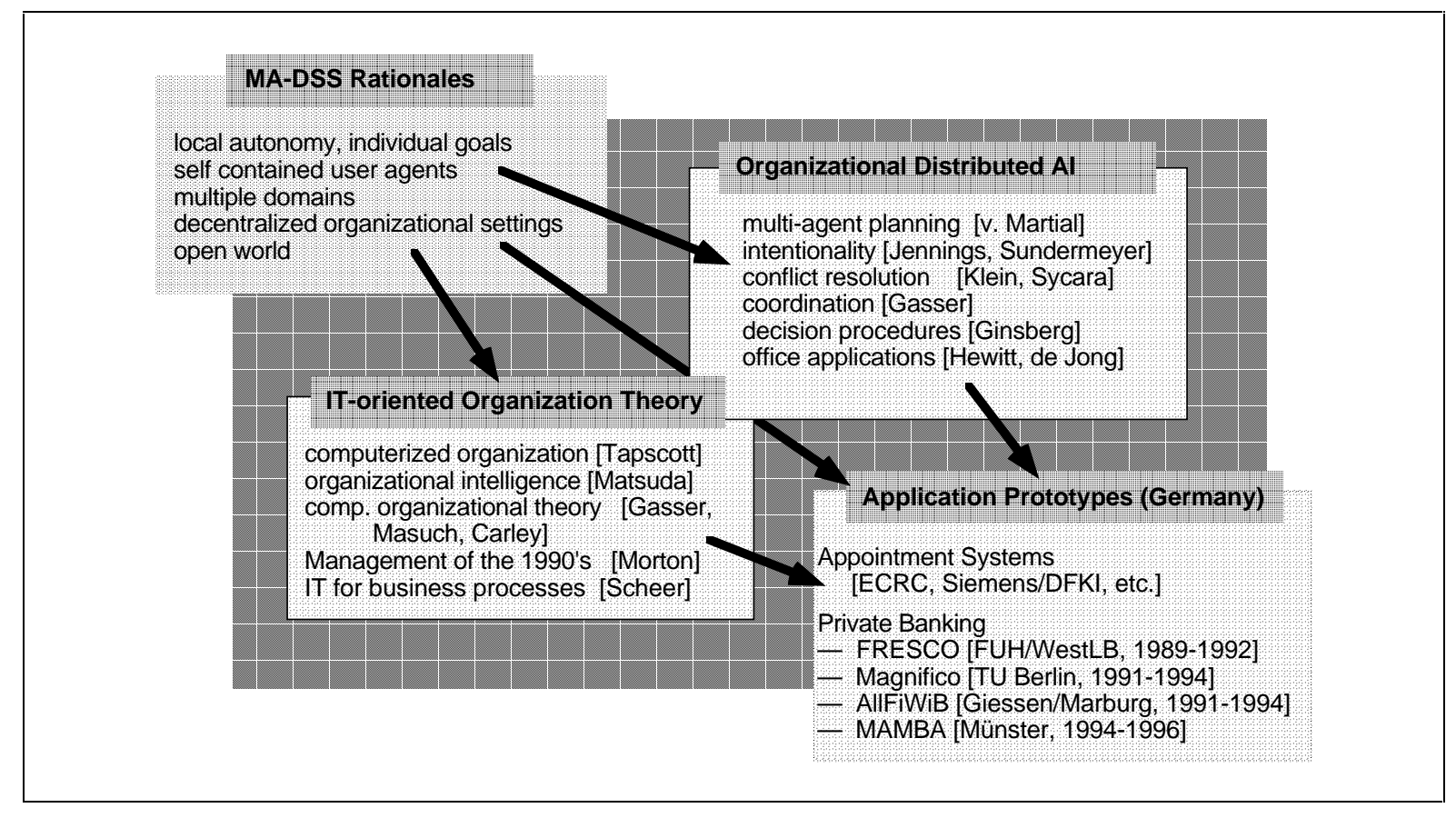

Figure 5: Rationales of Multi-Agent Decision Support Systems

It is beyond the scope of this paper to fully develop a research agenda in multi-agent decision support systems. Although, Figure 5 depicts some of the most important questions that are currently approached by research in what one may call organizational distributed artificial intelligence, and information technology-oriented organization theory. In the past, the major problem was to involve distributed artificial intelligence technology into productive decision support applications. This, however, may have already started to change. For instance, in 1992 a five years national research program has been launched in Germany that addresses distributed information system applications in business and management (König et.al., 1995). The mission of this research program is to provide solutions, that meet the urgent demand of industry for information processing technology in order to support knowledge processing in loosely coupled organizations such as adhocracies, virtual organizations, and strategic networks. Within that program, eight out of 22 projects base their technical approach on distributed artificial intelligence. However, in contrast to earlier research in distributed artificial intelligence, these projects are strongly application-driven. Typically, the research teams involve experts from management science and distributed artificial intelligence, and they are working in close cooperation with industry. 


\subsection{Human Computer Cooperative Work}

Evolving from the United Kingdom's mid-eighties Alvey Initiatives Human-Computer Cooperation (HCC) project (Smyth and Clarke, 1990), the idea of integrating computational agents with the human organization has gained great attention in literature (Steiner et.al., 1990; de Greef et.al., 1991; Kirn et.al., 1994). The goal of the HCC project "... was to develop a singleuser cooperative mechanism where the generation of a satisfactory solution could be enhanced by a machine having the ability to generate alternative and supplementary information based on a solution proposed by the user" (Smyth, 1994, p. 7). While this early approach did never aim to develop software agents, recent work on human computer cooperation is being applied to scenarios that involve multiple humans cooperating with multiple software agents (Steiner et.al., 1990). Within this context here, it seems fairly clear that the concept of human computer cooperation is of great interest to any research on computerized organizations. However, a brief review of recent work reveals important open problems, and it even identifies major research areas that remain to be addressed.

Research on human computer cooperative work is carried out in numerous disciplines, such as computer supported cooperative work, office information systems, intelligent user interfaces, artificial intelligence, and, in particular, distributed artificial intelligence. There is a great awareness, regarding the importance of doing interdisciplinary research across these disciplines. However, only little work so far has addressed how to coordinate distinct research approaches, and how to integrate results that emerge from different fields of interest.

As part of the ESPRIT II project Imagine, first steps have been undertaken developing towards a framework of human computer cooperative work. By this work, human computer cooperative work has been defined "... loosely as cooperative work involving many human agents and many system agents" (de Greef et.al., 1991). It first reviewed the respective theoretical foundations such as organization theory (Mintzberg, 1979), human-computer interaction, structured analysis (Yourdon, 1989), linguistic approaches (Cohen and Perrault, 1981; Levin and Moore, 1977), mathematical game theory (Axelrod, 1984), and distributed artificial intelligence (Bond and Gasser, 1988). On that basis, a set of research perspectives has been presented, as there are a task oriented perspective, a communicative and / or tool perspective, an ecological perspective, a democratic perspective, and failure explanation and prevention. At the end, the approach identified three orthogonal design dimensions that span a space in which any system could be represented as a point (Figure 6).

The cooperation dimension refers to concepts of cooperation within software-based multiagent systems emerging from distributed artificial intelligence. This also involves the question how appropriate user interfaces can be developed that fit with the interaction requirements 
imposed by a human computer cooperative work scenario. The supervisor dimension points to the command and control agent(s) of a human computer cooperative work system. Finally, the tool dimension can be associated with support for human-human cooperative work, like as in the domain of computer supported cooperative work.

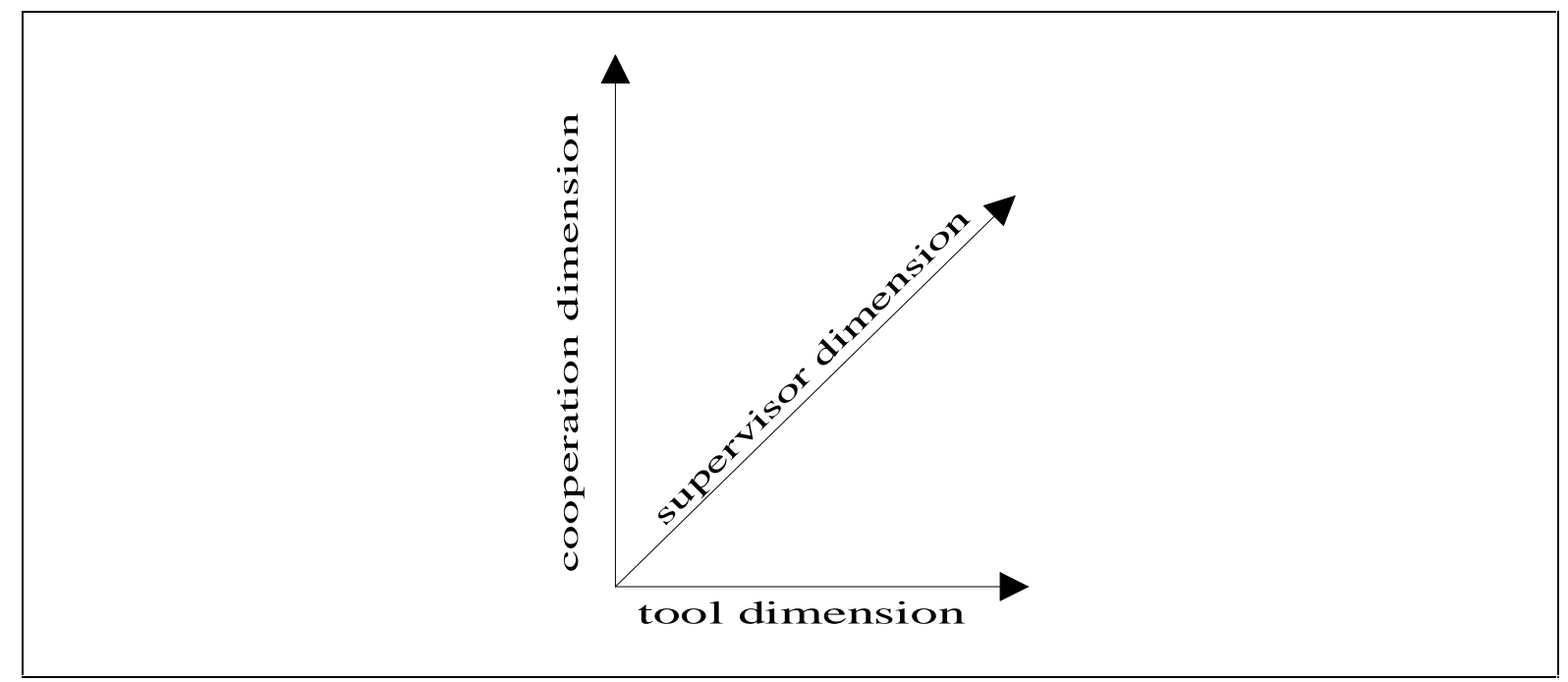

Figure 6: Human Computer Cooperative Work Design Dimensions

There has been a great deal of work in different scientific disciplines addressing issues that, in some way, relate to human computer cooperative work. Besides developing towards new information processing technologies, the basic motivation in doing such work is mainly to support humans being employed in more or less computerized enterprises. Among the most active disciplines there are computer supported cooperative work, distributed artificial intelligence, and human computer interaction. In contrast, there is only little (if any) work in organizational research that addresses how computational (knowledge-based) agents could be incorporated, on a human-like level, into organization theory. A closer look reveals that software agents are subsumed under the information processing system, which is assumed to be a black box-like passive component of the organization. In the first view, this may be reasonable from the perspective of organizations in that it keeps the focus of work on relations among humans. However, this approach is a major drawback of current research, because it impedes information processing technology to becoming closely connected with organizational research. 


\section{Organizational Applications}

Applying to the emergent relevance of information-integrated enterprises we are now going to discuss some applications of cooperative knowledge processing in computerized organizations. Most organizational activities require to select, evaluate, and process individual and organizational knowledge. We thus apply to a decision-oriented approach (Kirn, 1992) in order to classify knowledge processing activities according to the phases of decision making:

1. Problem Identification: The first phase requires organizations to focus their attention towards the most important tasks, and problems.

2. Knowledge Discovery: The second phase involves to identify, and select those capabilities that can effectively support solving the problem at hand.

3. Planning: The third phase develops an appropriate organizational problem solving strategy (plan), allocates the resources required, and identifies potential coordination tasks. Planning may be performed by one single member, or by a collaborative effort of several members of the organization.

4. Plan Execution: This requires the members of organization to process their individual tasks according to the plan to which they have applied.

5. Evaluation of Results: In the last phase, results are checked in order to terminate problem solving, or to trigger a new problem solving procedure.

To varying degrees, all these phases involve cooperative knowledge processing. We, thus, examine in more detail the relevance of cooperative knowledge processing to organizational attention focusing capabilities, knowledge discovery, and process management. The latter integrates the tasks of planning, and plan (process) execution. Finally, it is discussed how self organization skills can be introduced into process oriented, computerized organizations.

\subsection{Attention Focusing Capabilities}

It has been argued that the real scarce organizational resource is the one of attention focusing capabilities (Blanning et.al., 1992). The relevance of this problem is directly related to the degree of decentralization, the acceleration of information flow, and the ever increasing dynamics and complexity of the environment of organizations. 
The capability of an organization to focus its attention on the most important problems, and events depends (1) upon the respective individual capabilities of its members, and (2) upon the organizational capability to coordinate individual behavior towards global goals. The capability of individuals to focus their attention involves two distinct issues:

1. Taxonomy of local goals: In an organizational context, individuals pursue informal (private), and formal (organizational) goals. In general, it is assumed that individuals aim at maximizing their local utility that is supposed to being positively correlated to the degree to which they achieve their local goals. An important limitation has been identified that of bounded rationality (March and Simon, 1958).

2. Information filtering: In order to approach their local goals individuals need to filter, and to assess incoming information. Due to the increasing availability of electronic media, knowledge workers are suffering from information overload. Thus, information filtering mechanisms are required through which the limited information processing capabilities of humans can be allocated to the most important tasks and problems.

This has given rise to develop information filtering agents (ACM, 1994). These are capable to evaluate information with respect to local goals, for instance through search for predefined keywords, role descriptions, deadlines, contextual information, or with respect to deep models of an application. Above all, information filtering agents relate to personal assistants.

In an organizational context, humans are cooperating, and collaborating with others of the same, and of other enterprises. Thus, attention focusing capabilities also involve an enterprisewide perspective, which requires information filtering agents to collaborate in order to adapt their filtering work to their organizational environment. This, in turn, requires them to coordinate local goals towards global aims and objectives, to collaboratively identify important global problems, and to draw appropriate conclusions for those filtering criteria they are applying on their local level. In this view, cooperative information filtering agents either relate to multiagent decision support systems, or to human computer cooperative work.

\subsection{Knowledge Discovery}

The second phase of organizational problem solving requires to identify, and select those pieces of knowledge that can help to solve the problem at hand. In general, a diversity of knowledge sources will be able to contribute to a particular task. In our context here, knowledge sources are assumed to be under decentralized control, aiming to contribute to a maximum of global organizational productivity (benevolent agents). 
This scenario inherently involves knowledge processing, and it necessarily requires a cooperative style of problem solving. Since long, distributed artificial intelligence techniques have been employed to approach the problem of knowledge discovery in decentralized environments (Kirn, 1992). More recently, the rapidly increasing availability of information within the internet has attracted people to develop knowledge discovery agents that browse the internet. Again, these agents firstly relate to the area of personal assistants. However, due to the complexity of the internet (and similar knowledge sources) future knowledge discovery agents will perform their work in parallel, and cooperatively. This will transform the concept of knowledge discovery agents into that of a multi-agent decision support system, where the different knowledge discovery agents perform their search in close collaboration

\subsection{Business Process Orientation}

There is already a large body of literature originating from organization theory and management science as well as from Distributed AI, which argues that numerous problems in business and organizations could be quite naturally addressed by a multi-agent system approach. Some prominent examples are the virtual enterprise (Davidow and Malone, 1992) and the fractalization of organizations (Warnecke, 1991), the modeling and simulation of enterprises (Fox, 1981), the efforts towards an integrated coordination theory (Malone, 1987), support of business processes and workflows (Malone et al, 1993), and enterprise integration (Petrie Jr., 1992).

\subsubsection{Overview}

The organizational model presented above applied to a static, and a dynamic perspective. The static organizational structure establishes durable relationships between humans, and computational members of an organization. The dynamic perspective is process-oriented, thus describing how humans and computational agents cooperate, and collaborate in order to achieve at common goals. The question is, how this affects the concept of process orientation. With respect to the type of agents involved, three different process scenarios can be identified:

1. Humans only are involved. This scenario refers to the current discussion in the literature. Software systems may be involved also, supposed that they do not apply to an organizational role (for instance text processors, electronic spreadsheets).

2. Humans and computational agents are involved. This provides for partially computerized processes and workflows. It requires us to integrate human and computer-based problem 
solving (human computer cooperative work), to design intelligent user interfaces in order to enable humans collaborating with computational agents, and to provide coordination mechanisms being able to cope with interactions between humans and self-contained software agents.

3. Computational agents only are involved. Thus, processes and workflows are fully computerized. The main concern, thus, is on representation, management, and control of softwarebased processes (Kirn et.al., 1994).

Referring to Table 1, the first point is a subfield of traditional organization theory. Due to the dominant role of human computer interfaces, the second point relates primarily to the field of personal assistants. Further research topics may relate either to multi-agent decision support systems, or to human computer cooperative work. Finally, the third point refers to distributed artificial intelligence. This area is of increasing relevance because of the evolving computerization of organizations. Two questions arise:

1. How can cooperation and collaboration between such computational agents be related to process-oriented models of organizations?

2. How can distributed artificial intelligence contribute to adapt and create, coordinate, and control computerized processes that are embedded into an organizational context?

We have argued elsewhere that the first problem can be approached by taking advantage from the conceptual similarity between processes (and workflows), and multi-agent plans in distributed artificial intelligence (Kirn et.al., 1994). We are aware that, even on the conceptual level, there are still some differences between these two concepts. Nevertheless, multi-agent planning provides powerful techniques by which processes and workflows can be represented, evaluated, and controlled.

The second point involves three distinct topics: customization of processes, coordination of interacting processes, and organizational flexibility.

\subsubsection{Customization of Processes}

The basic idea behind the shift to business processes is that of enterprise-wide customer orientation. Customer orientation firstly requires enterprises to classify their customers with respect to the preferences they exhibit. Then, they shape new (or redesign existing) products so that the preferences of a typical customer in such groups can best be addressed. Accordingly, the 
respective processes need to be (re-)designed with respect to the enterprises' aims and objectives.

However, in order to survive on dynamic markets enterprises need being able to customize their products, and, thus, their processes to new, or changing customer demands. Customization of a process can be achieved either by adapting a single process to the individual preferences of a particular customer, or by creating configurations of processes in order to meet more complex preference portfolios. This, in turn, requires organizations to provide a set of well-shaped processes representing elementary products (lean processes) together with a set of powerful operators by which customized process configurations (smart process management) can be provided. Further, process customization does also include to discover, evaluate and resolve interactions between distinct processes that perform in parallel. Process customization is performed on the operative layer of process management.

Figure 8 demonstrates the basic idea behind process customization: From a set of available scripts, workflows and processes those are selected that can contribute to a task at hand. The second step involves to create (and optimize) a process configuration that can efficiently address a complex portfolio of preferences of a particular customer. The third step, then, is to operate this process configuration. This, in turn, involves coordination in order to detect, and to resolve inter- and intra-process relationships.

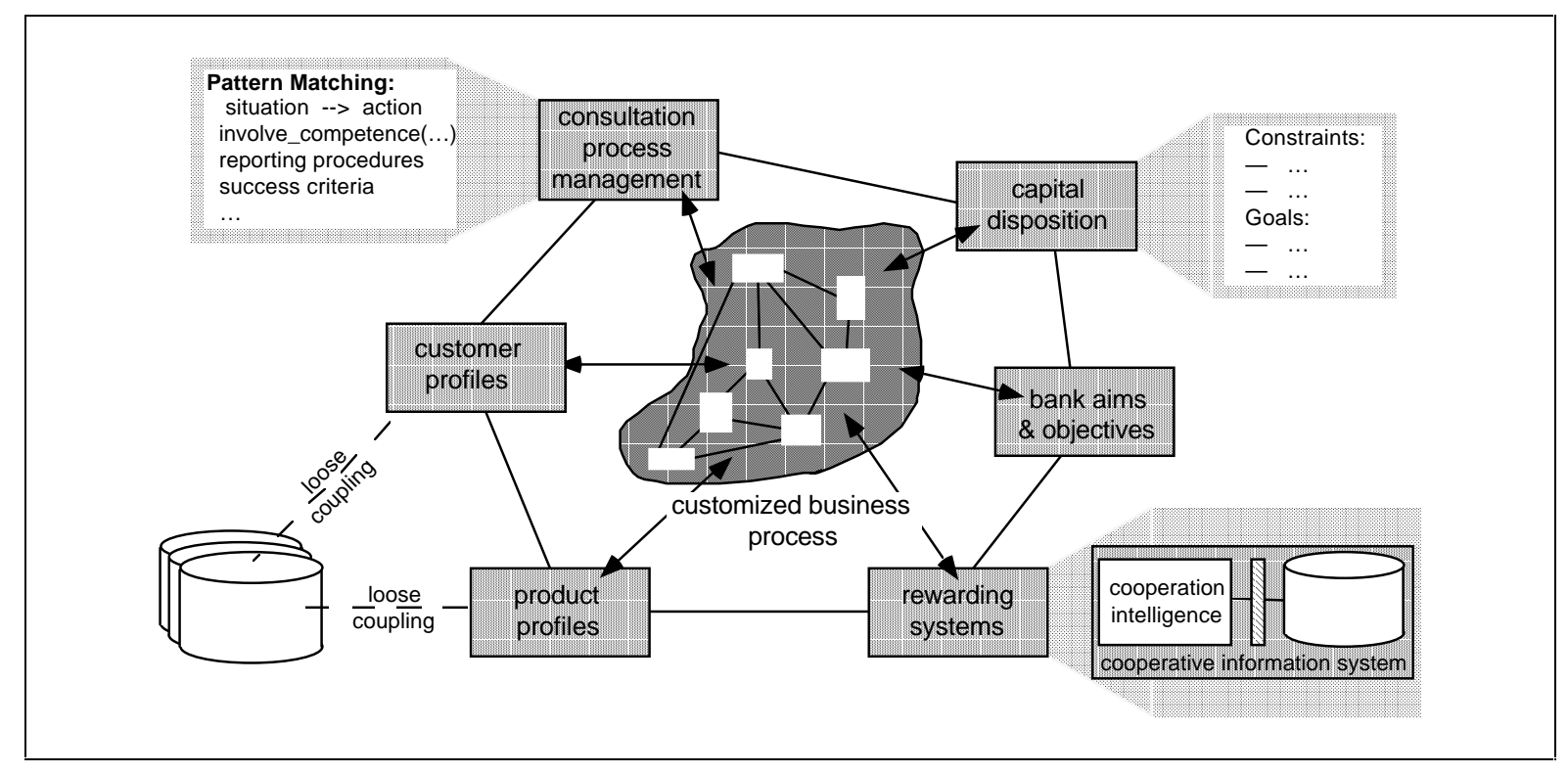

Figure 8: Customization of Business Processes 
In contrast to traditional approaches (e.g., Gaitanides), process coordination is charged with adapting scripts, workflows and processes to the preferences of (a group of) customers, rather than dealing with interdependencies that exist between small subtasks being under the responsibility of distinct organizational units. This requires organizational fractals to exhibit extensive coordinative capabilities. Thus, going far beyond today's concept of workflow management, future process management systems must be capable to efficiently support organizational flexibility through a diversity of methods of process customization. It has been argued recently, that this can efficiently be supported by methods of multi-agent planning. For more details, the reader is referred to recently published work (Kirn et.al., 1994; v. Martial, 1992).

\subsubsection{Coordination of Interacting Organizational Processes}

Typically, within organizations a large number of processes are performing in parallel. Due to interacting goals, conflicting resource allocations, and the like, these processes cannot be operated in isolation. Processes may further interact with their environments. Interactions between processes, or between a process and its environment, can be classified through three distinct dimensions:

First, process interactions may be classified with respect to the consequences that arise (v. Martial, 1992):

1. Positive relationship: There exists a positive relationship between two processes $\mathrm{A}$ and $\mathrm{B}$, if and only if either the result of $\mathrm{A}$, or the outcome of $\mathrm{B}$, or the outcome of both processes is being improved through the interaction of process A with process $\mathrm{B}$.

2. Neutral relationship: There exists a neutral relationship between two processes A and B, if and only if neither the result of $\mathrm{A}$, nor the outcome of $\mathrm{B}$, nor the outcome of both processes in combination will be affected by the interaction of process A with process B.

3. Negative relationship: There exists a negative relationship between two processes A and B, if and only if either the result of $\mathrm{A}$, or the outcome of $\mathrm{B}$, or the outcome of both processes gets worse through the interaction of process A with process B.

Second, four distinct process interaction types can be identified:

1. Goal conflicts: Goal conflicts arise from local autonomy. Resolving goal conflicts requires the agents (or organizational units) involved to apply sophisticated conflict resolution mechanisms, for instance negotiation-based approaches (Kuwabara and Lesser, 1990), plan coordination (v. Martial, 1992), or persuasion (Sycara, 1985). 
2. Shared objects: An object $O$ is shared by two or more processes, if $O$ is concurrently accessed (read, write, delete) through these processes. Shared objects are assumed to be non-consumable. However, they are bottle-necks within a system, in that they require to sequentialize partial processes, workflows, and activities that are under decentralized control.

3. Shared resources: Shared resources are consumable. Thus, whenever a shared resource is accessed by a process, this process consumes a portion of that resource. As there is no unlimited availability of resources, the order in which processes have access to shared resources affects directly the efficiency of the whole system.

4. Environment: Each process is operated within a particular process environment. From the perspective of a single process, some parts of this environment are static while others are dynamic. It has been argued, that processes may also change their environments, which, in turn, may affect their own behavior in subsequent periods.

Third, interactions can also being classified with respect to the time dimension involved:

1. Static process interactions, that are detected, and resolved before execution time.

2. Dynamic process interactions, that are detected before, and resolved at execution time.

3. Dynamic process interactions, that are detected, and resolved at execution time.

Evolving from recent work in distributed artificial intelligence, several coordination mechanisms have been suggested which all apply to widespread decentralization of the whole system, and which sustain the local autonomy of each agent involved. Examples are partial global planning (Decker and Lesser, 1992), plan coordination (v. Martial, 1992; Sycara, 1989), or persuasion (Sycara, 1985). Each of these coordination mechanisms has the potential to resolve the one, or the other of the interaction types described above.

\subsection{Self Organization Skills}

According to recent discussions in the literature (Warnecke, 1991), the ability to reorganize structure, and behavior is one of the most important skills of future organizations.

The organizational model presented above was built upon the concepts of computerization, radical decentralization, and process orientation. We have already mentioned that self-contained 
organizational units are process providers. While process customization referred to the ability of fractals to adapt their processes to changing customer demands, the ability of an enterprise to reorganize its structures, and (business) processes refers to its ability to integrate processes of different organizational units in order to (re-)design its enterprise-wide organizational capabilities. Figure 9 demonstrates the basic idea that stands behind the idea of process integration.

Applying to computational agents, distributed artificial intelligence has already addressed a great deal of work towards developing self organization skills of multi-agent systems (Corkill, 1982; Ishida, 1992; Sugawara and Lesser, 1993). This work was mainly concerned with self organization on the level of single atomic activities and (re-)design of organizational structures. Within our context, self organization primarily addresses processes, thus referring to the tactical level of process management. It has been demonstrated recently, that self organization of systems of computational agents can also be designed on the basis of processes (Kirn et.al., 1994).

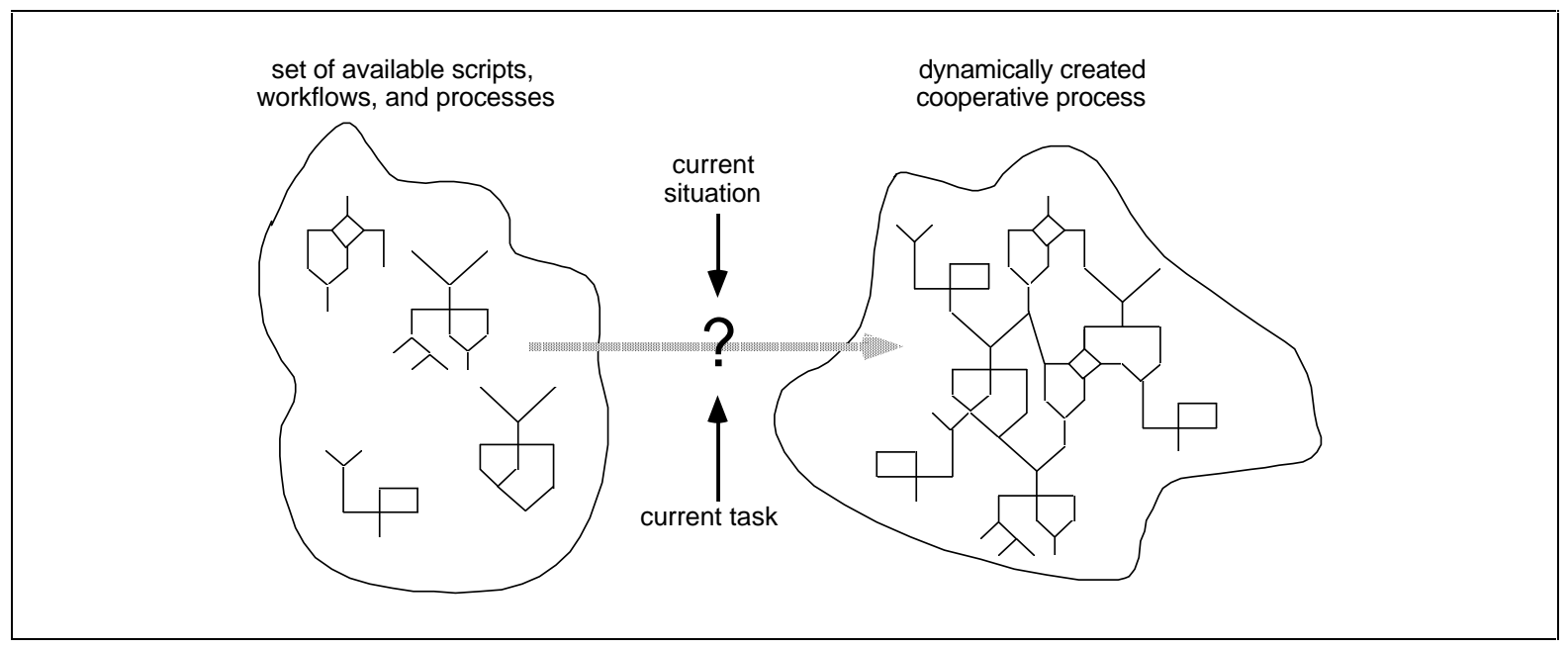

Figure 9: Integration of Business Processes

\section{Summary}

There is a growing understanding that today's organizations are seriously challenged by just-intime availability of information, worldwide competition on dynamic markets and the ever increasing complexity of political, social and ecological settings. In order to cope with these challenges a variety of organizational strategies has been developed. Out of them, radical decentralization and business process orientation are the most prominent ones. The implemen- 
tation of these strategies is accompanied by fundamental advances in information technology, and, in particular, in information processing technology. The Management of the 1990's program has revealed that these advances will have major impacts on the definition, structure, function, and capabilities of future organizations.

Drawing from these understandings, the paper assumes that future organizations will be significantly computerized, and widespread decentralized. On this basis, we first reviewed how the integration of information processing into organization theory has evolved. This has revealed, that we still lack a comprehensive integration of research in information processing and organization theory. This impedes modern information processing technologies from efficiently contributing to meet the challenges today's organizations are faced with.

Next, business process orientation has been addressed, which is perhaps the most important organizational strategy today. An agent-oriented approach to business process orientation has been presented, which firstly regarded each organizational entity (human or computational agents, organizational units) as a provider of sequences of activities (scripts, workflows, processes) rather than applying to an approach of task decomposition and allocation. In this context we demonstrated that coordinating sequences of activities that are under decentralized, (more or less) autonomous control necessitates cooperative styles of problem solving.

According to the number of agents, cooperative knowledge processing can be classified into six distinct areas. Due to recent progress in network technologies, we have argued that multiagent decision support systems and human computer cooperative work are of particular interest in organizational settings. Both fields utilize techniques developed within distributed artificial intelligence, by which software agents are enabled to collaboratively work on common problems in order to achieve at global aims.

Finally, several organizational applications of cooperative knowledge processing technology have been discussed. These addressed important issues such as attention focusing capabilities of organizations, knowledge discovery, customization of processes, coordination of interacting processes, and self organization skills of process-oriented, computerized enterprises.

The discussion of this paper has demonstrated that cooperative knowledge processing technologies exhibit quite a high potential for future organizations, for instance in that they enhance intellectual organizational skills, improve the responsiveness of enterprises to their environments, and efficiently coordinate decentralized activities towards global organizational aims. 


\section{References}

ACM, Special Issue on Intelligent Agents. Communications of the ACM, Volume 37, Number 8, August 1994.

Axelrod, R., The Evolution of Cooperation. Basic Books, New York, 1984.

Blanning et.al., R.W., King, D.R., Marden, J.R. and Seror, A.C.: Intelligent Models of Human Organizations: The State of the Art. Journal of Organizational Computing, 2 1992, pp. 123-130.

Bocionek, S., Software Secretary Kernel: An Extendable Architecture for Learning and Negotiating Personal Assistants. ai communications 7 (3/4) 1994, pp. 147-160.

Bond, A. and Gasser, L., Readings in Distributed Artificial Intelligence. Morgan Kaufmann Publishers, San Mateo, CA., 1988.

Carley, K.M. amd Prietula, M.J., Computational Organization Theory, Lawrence Erlbaum, 1994.

Cohen, P.R. and Levesque, H.J., On Acting Together: Joint Intentions for Collective Actions. In Workshop on Distributed AI, 1988.

Cohen, P.R. and Perrault, C.R., Elements of a Plan-Based Theory of Speech Acts. In Nilsson, N.J. and Webber, B.L. (eds.), Readings in Artificial Intelligence. Morgan Kaufman, 1981.

Conry, S.E., Meyer, R.A. and Lesser, V.R., Multistage Negotiation in Distributed Planning. COINTS Technical Report 86-67, Amherst, MA. December 1986.

Corkill, D., A Framework for Organizational Self-Design in Distributed Problem Solving Networks. Ph.D. Thesis. Department of Computer and Information Science, Univ. of Massachusetts at Amherst, MA. COINS-TR-82-33. Dec. 1982.

Davenport, T.H., Process Innovation: Reengineering Work through Information Technology. Harvard Business School Press, Boston, Mass., 1993.

Davidow, W.H. and Malone, M.S., The Virtual Corporation. Structuring and Revitalizing the Corporation for the 21st Century. Harper Collins Publishers, 1992.

Davis, R. and Smith, R.G., Negotiation as a Metaphor for Distributed Problem Solving. AI 20, pp. 63.

Decker, K. and Lesser, V., Generalizing the Partial Global Planning Algorithm. International Journal of Intelligent \& Cooperative Information Systems, Vol. 1, No. 2; June 1992, pp. 319-346.

de Greef, P., Mahling, D., Neerincx, M. and Wyatt, S., Analysis of Human-Computer Cooperative Work. In: Haugeneder, H. (ed.), Imagine Final Project Report, Chapter 2. Munich 1994, pp. 17-38.

de Greef, P., Human-Computer Cooperative Work. Imagine Technical Report Series, Technical Report No. 4, Munich 1991.de Jong, P., A Framework for the Development of Distributed Organizations. Proceedings of the IJCAI-91 Workshop on Intelligent and Cooperative Information Systems: Bringing AI and Information Systems Technology Together, Darling Harbour, Sydney, Australia, August 25, 1991, pp. 1.

Durfee, E.H. and Lesser, V.R., Using Partial Global Plans to Coordinate Distributed Problem Solvers. IJCAI-87, pp. 875. 
Elofson, G.S. and Konsynski, B.R., Performing Organisational Learning with Machine Apprentices. Decision Support Systems 10 (1993), pp. 109-119.

Farhoodi, F., Proffitt, J., Woodman, P. and Tunnicliffe, A., Design of Organisations in Distributed Decision Systems. AAAI-Workshop on Cooperation Among Heterogeneous Intelligent Systems, 1991.

Fox, M.S., An Organizational View of Distributed Systems. IEEE Transactions on Systems, Man and Cybernetics, SMC-11, 1981, pp. 70-80.

Fox, M.S., The TOVE project: Towards a Common Sense Model of the Enterprise, Proc. of the 5th International Conference, IEA/AIE-92 on Industrial and Engineering Applications of Artificial Intelligence and Expert Systems, Paderborn, June 1992, Springer Verlag, LNAI 604, pp. 25.

Gaitanides, M., Prozeßorganisation. Verlag Vahlen, München 1982 (in German).

Gasser, L., DAI Approaches to Coordination. In Avouris, N.M. and Gasser, L. (eds.), Distributed Artificial Intelligence: Theory and Practice, Kluwer Academic Publishers, 1992, pp. 31-52.

Ginsberg, M., Decision Procedures. In M. Huhns (ed.), Distributed Artificial Intelligence. Morgan Kaufman Publishers, 1987, pp. 3-28.

Gutenberg, E., Grundlagen der Betriebswirtschaftslehre. Erster Band: Die Produktion. Springer-Verlag, Berlin, Heidelberg, New York 1951 (in German).

Hammer, M. and Champy, J., Reengineering the Corporation. Harper Collins Publisher, New York, 1991.

Hastings, C, The New Organization: Growing the Culture of Organizational Networking. McGraw Hill, London et.al., 1993.

Hoschka, P., Assisting Computer - A New Generation of Support Systems. In Brauer, W. and Hernández, D. (Hrsg.), Verteilte Künstliche Intelligenz und Kooperatives Arbeiten, Proceedings 4. Intern. GI-Kongresses Wissensbasierte Systeme, München, Oktober 1991, S. 219-230.

Huber, G.P. and McDaniel, R.R., The Decision-Making Paradigm of Organizational Design. Management Science Vol 32, 1986, p. 572-589.

Ishida, T., The Tower of Babel: Towards Organization-Centered Problem-Solving. In Working Papers of the 11th International Workshop on Distributed Artificial Intelligence, Glen Arbor, Michigan. February 25-29, 1992, pp. 141-153.

Jin, Y. and Levitt, R.E., i-Agents: Modeling Organizational Problem Solving in Multi-Agent Teams, Intelligent Systems in Accounting, Finance and Management Vol. 2, Issue 4, 1993, pp. 247-270.

Kirn, St., Cooperative Ability of Intelligent Agents in Federative Environments. PhD thesis, FernUniversität Hagen, 1992 (in German).

Kirn, St., "Organisationale Intelligenz" durch kooperative Mensch-Computer-Systeme. In: R. Thome (Hrsg.): Kommunikation und Oberflächen bei Banken, Bausparkassen und Versicherungen. compuTeam Würzburg, 1993, S. 231-245 (in German). 
Kirn, St., Supporting Human Experts Collaborative Work: Modelling Organizational Context Knowledge in Cooperative Information Systems. In John H. Connolly, Ernest Edmonds (eds.), CSCW and AI. Springer-Verlag. CSCW Series. Spring 1994, pp. 127-140.

Kirn, St. and Schlageter, G., Intelligent Agents in Federative Expert Systems: Concepts and Implementation. In Deen, M. (ed.), Cooperating Knowledge Based Systems. Springer. Berlin, Heidelberg, New York et.al., 1991, pp. 53-78.

Kirn, St. and O'Hare, G. (eds.), Towards the Intelligent Organisation: The Coordination Perspective. Springer-Verlag, London et.al., 1995.

Kirn, St., Unland, R. and Wanka, U., MAMBA: Automatic Customization of Computerized Business Processes. Information Systems, Vol. 19, No. 8, pp. 661-682, December 1994.

König, W., Kurbel, K., Mertens, P. and Pressmar, D. (eds.): Distributed Information Systems in Business and Management. John Wiley and Sons. Spring 1995.

Kuwabara, K. and Lesser, V.R., Extended Protocol for Multi-Stage Negotiation. Proceedings of the 9th International Workshop on Distributed AI. Bandera, Texas. October 23-27, 1990.

Levin, J.A. and Moore, J.A., Dialogue-Games: Metacommunication Structures for Natural Language Interaction. Cognitive Science, 1977, pp. 395-420.

Levitt, R.E. et.al., The "Virtual Design team": Simulating How Organization Structure and Information Processing Affect Team Performance. In: Carley, K.M. amd Prietula, M.J., Computational Organization Theory, Lawrence Erlbaum, 1994, pp. 1-18.

Malone, T., W. and Crowston, K., What is Coordination Theory and How Can it Help Design Cooperative Work Systems? Proceedings Conference on Computer Supported Cooperative Work (CSCW), Los Angeles, CA, 1990.

Malone, T. and Crowston, K., The Interdisciplinary Study of Coordination. CCS WP \#157, Sloan School WP \#3630-93. Massachusetts Institute of Technology, Sloan School of Management, Cambridge, Mass., November 1993.

Malone, T., Crowston, K., Lee, J. and Pentland, B., Tools for inventing organizations: Toward a handbook of organizational processes. CCS WP \#141, Sloan School WP \#3562-93. Massachusetts Institute of Technology, Sloan School of Management, Cambridge, Mass., May 1993.

Malone, T., Modeling Coordination in Organizations and Markets. Management Science, 33 (1987) 10, S. 1317-1332.

Malone, T., Organizing Information Processing Systems: Parallels Between Human Organizations and Computer Systems. In W. Zachary, S. Robertson and J. Black (eds.), Cognition, Cooperation, and Computation. Ablex Publishing Corporation, Norwood, NJ, 1988.

March, J.G. and Simon, H.A., Organizations. New York 1958.

v. Martial, F., Coordinating Plans of Autonomous Agents. Lecture Notes in Artificial Intelligence, No. 610. Springer-Verlag, Berlin, Heidelberg. Germany 1992.

Masuch, M. (ed.), Organization, management, and expert systems. New York, Walter de Gruyter 1990. 
Matsuda, T., Organizational Intelligence: Its Significance as a Process and as a Product. In Proceedings of CEMIT92/CECOIA 3 - International Conference on Economics, Management and Information Technology Tokio 1992, pp. 219-222.

Mintzberg, H., The Structuring of Organizations. Prentice-Hall, 1979.

Morton, S. (ed.), The Corporation of the 1990s. Oxford University Press. New York, Oxford 1991.

Newell, A., The Knowledge Level. AI 18, 1982, pp. 86.

Numaoka, C. and Tokoro, M., Conversation Among Situated Agents. In Proceedings of the 10th Workshop on Distributed AI, Chapter 13, Bandera, Texas, October 23-27, 1990.

Numaoka, C., A Conceptual Framework for Modeling Conversation in Open Distributed Systems. Ph. D. Thesis. Keio University, Department of Electrical Engineering. Yokohama, Japan. 1991.

Pattison, H.E., Corkill, G.G. and Lesser, V.R., Instantiating Descriptions of Organizational Structures. In Huhns, M. (ed.), Distributed AI, 1987, pp. 311.

Petrie Jr., C.J., Enterprise Integration Modeling. Proceedings of the First International Conference, MIT Press, Cambridge, Mass., 1992.

Porter, M.E., Competitive Advantage: Creating and Sustaining Superior Performance. New York, Free Press, 1985.

Scheer, A.-W., Wirtschaftsinformatik: Referenzmodelle für industrielle Geschäftsprozesse. SpringerVerlag Berlin, Heidelberg, New York, 1994 (in German).

Simoudis, E., and Adler, M., Integrating Distributed Expertise. International Journal of Intelligent and Cooperative Information Systems, Vol. 1, No. 3 \& 4, 1992, pp. 393-410.

Singh, M., Group Ability and Structure. In Preproceedings of the Second European Workshop on "Modelizing Autonomous Agents and Multiagent Worlds" (MAAMAW-90), Saint-Quentin en Yvelines, France, 1990. S. 85-100.

Smith, R. and Davis, R., Frameworks for Cooperation in Distributed Problem Solving. IEEE Transactions on Systems, Man and Cybernetics, SMC-11/1, 1981, pp. 61-70

Smith, R.G., A Framework for Distributed Problem Solving. Proceedings of the Joint International Conference on AI, pp. 836.

Smyth, M., Towards a Cooperative Agent. In John H. Connolly, Ernest Edmonds (eds.), CSCW and AI. Springer-Verlag. CSCW Series. Spring 1994, pp. 1-12.

Smyth, M. and Clarke, A.A., Human-Human Cooperation and the Design of Cooperative Machines. ICL Technical Journal, Vol. 7, Number 1, 1990, pp. 110-127.

Sridharan, N.S., 1986 Workshop on Distributed AI. AI Magazine, Fall 1987, pp. 75.

Stary, C., Model-Based Design Bases for Task-Oriented Applications. International Conference on Data Engineering (ICDE-93), Wien, Austria, 21.-23. April 1993. 
Steiner, D., Mahling, D. and Haugeneder, H., Human Computer Cooperative Work. In: Proceedings of the 10th International Workshop on Distributed Artificial Intelligence. MCC Technical Report ACT-AI-355-90, Austin, Texas, 1990.

Stephens, L. and Merx, M., Agent Organization as an Effector of DAI System Performance. Ninth Workshop on Distributed Artificial Intelligence, Rosario Resort, Eastsound, Washington, September 12-14, 1989, S. 263-292.

Stolze, M., Task Level Framework for Cooperative Expert Systems Design. ai communications, Vol. 4 (1991) No. 2/3, pp. 98.

Suchman, L., Plans and Situated Actions: The Problem of Human-Machine-Communication. Cambridge University Press, New York, 1987.

Sugawara, T. and Lesser, V.: On-Line Learning of Coordination Plans. In: Proceedings of the 12th International Workshop on Distributed Artificial Intelligence, Hidden Valley, Pensylvania, May 1921, 1993, pp. 335-355.

Sycara, K.P., Arguments of Persuasion in Labor Mediation. Proceedings 1985 International Joint Conference on Artificial Intelligence (IJCAI-85).

Sycara, K.P., Argumentation: Planning other Agents' Plans. Proceedings 1989 International Joint Conference on Artificial Intelligence (IJCAI-89), pp. 517-523.

Tapscott, D. and Caston, A., Paradigm Shift - The New Promise of Information Technology. McGrawHill, Inc., New York et.al., 1993.

Taylor, F.W., Die Grundsätze wissenschaftlicher Betriebsführung, München 1919 (in German).

Thurow, L.C., Foreword. In Morton, S. (ed.), The Corporation of the 1990s. Oxford University Press. New York, Oxford 1991.

Warnecke, H.-J., Die Fraktale Fabrik — Revolution der Unternehmenskultur, Springer-Verlag, 1991 (in German).

Werkman, K., Using Negotiation and Coordination in Multiple Agent Systems. Proceedings of the IJCAI-91 Workshop on Intelligent and Cooperative Information Systems: Bringing AI and Information Systems Technology Together, Darling Harbour, Sydney, Australia, August 25, 1991.

Wolf, M., New Technologies for Customer Rating: Integration of Knowledge-Based Systems and Human Judgement. In this issue.

Yourdon, E., Modern Structured Analysis. Prentice Hall, Englewood Cliffs, N.J., 1989.

Zuboff, S., In the Age of the Smart Machine: The Future of Work and Power. New York, Basic Books, 1988. 


\section{Arbeitsberichte des Instituts für Wirtschaftsinformatik}

Nr. 1 Bolte, Ch., Kurbel, K., Moazzami, M., Pietsch, W.: Erfahrungen bei der Entwicklung eines Informationssystems auf RDBMS- und 4GL-Basis; Februar 1991.

Nr. 2 Kurbel, K.: Das technologische Umfeld der Informationsverarbeitung - Ein subjektiver 'State of the Art'-Report über Hardware, Software und Paradigmen; März 1991.

Nr. 3 Kurbel, K.: CA-Techniken und CIM; Mai 1991.

Nr. 4 Nietsch, M., Nietsch, T., Rautenstrauch, C., Rinschede, M., Siedentopf, J.: Anforderungen mittelständischer Industriebetriebe an einen elektronischen Leitstand - Ergebnisse einer Untersuchung bei zwölf Unternehmen; Juli 1991.

Nr. 5 Becker, J., Prischmann, M.: Konnektionistische Modelle - Grundlagen und Konzepte; September 1991.

Nr. 6 Grob, H.L.: Ein produktivitätsorientierter Ansatz zur Evaluierung von Beratungserfolgen; September 1991.

Nr. 7 Becker, J.: CIM und Logistik; Oktober 1991.

Nr. 8 Burgholz, M., Kurbel, K., Nietsch, Th., Rautenstrauch, C.: Erfahrungen bei der Entwicklung und Portierung eines elektronischen Leitstands; Januar 1992.

Nr. 9 Becker, J., Prischmann, M.: Anwendung konnektionistischer Systeme; Februar 1992.

Nr. 10 Becker, J.: Computer Integrated Manufacturing aus Sicht der Betriebswirtschaftslehre und der Wirtschaftsinformatik; April 1992.

Nr. 11 Kurbel, K., Dornhoff, P.: A System for Case-Based Effort Estimation for Software-Development Projects; Juli 1992.

Nr. 12 Dornhoff, P.: Aufwandsplanung zur Unterstützung des Managements von Softwareentwicklungsprojekten; August 1992.

Nr. 13 Eicker, S., Schnieder, T.: Reengineering; August 1992.

Nr. 14 Erkelenz, F.: KVD2 - Ein integriertes wissensbasiertes Modul zur Bemessung von Krankenhausverweildauern - Problemstellung, Konzeption und Realisierung; Dezember 1992.

Nr. 15 Horster, B., Schneider, B., Siedentopf, J.: Kriterien zur Auswahl konnektionistischer Verfahren für betriebliche Probleme; März 1993.

Nr. 16 Jung, R.: Wirtschaftlichkeitsfaktoren beim integrationsorientierten Reengineering: Verteilungsarchitektur und Integrationsschritte aus ökonomischer Sicht; Juli 1993.

Nr. 17 Miller, C., Weiland, R.: Der Übergang von proprietären zu offenen Systemen aus Sicht der Transaktionskostentheorie; Juli 1993.

Nr. 18 Becker, J., Rosemann, M.: Design for Logistics - Ein Beispiel für die logistikgerechte Gestaltung des Computer Integrated Manufacturing; Juli 1993.

Nr. 19 Becker, J., Rosemann, M.: Informationswirtschaftliche Integrationsschwerpunkte innerhalb der logistischen Subsysteme - Ein Beitrag zu einem produktionsübergreifenden Verständnis von CIM; Juli 1993. 
Nr. 20 Becker, J.: Neue Verfahren der entwurfs- und konstruktionsbegleitenden Kalkulation und ihre Grenzen in der praktischen Anwendung; Juli 1993.

Nr. 21 Becker, K., Prischmann, M.: VESKONN - Prototypische Umsetzung eines modularen Konzepts zur Konstruktionsunterstützung mit konnektionistischen Methoden; November 1993

Nr. 22 Schneider, B.: Neuronale Netze für betriebliche Anwendungen: Anwendungspotentiale und existierende Systeme; November 1993.

Nr. 23 Nietsch, T., Rautenstrauch, C., Rehfeldt, M., Rosemann, M., Turowski, K.: Ansätze für die Verbesserung von PPS-Systemen durch Fuzzy-Logik; Dezember 1993.

Nr. 24 Nietsch, M., Rinschede, M., Rautenstrauch, C.: Werkzeuggestützte Individualisierung des objektorientierten Leitstands ooL; Dezember 1993.

Nr. 25 Meckenstock, A., Unland, R., Zimmer, D.: Flexible Unterstützung kooperativer Entwurfsumgebungen durch einen Transaktions-Baukasten; Dezember 1993.

Nr. 26 Grob, H. L.: Computer Assisted Learning (CAL) durch Berechnungsexperimente; Januar 1994.

Nr. 27 Kirn, St., Unland, R. (Hrsg.): Tagungsband zum Workshop "Unterstützung Organisatorischer Prozesse durch CSCW". In Kooperation mit GI-Fachausschuß 5.5 "Betriebliche Kommunikations- und Informationssysteme" und Arbeitskreis 5.5.1 "Computer Supported Cooperative Work", Westfälische Wilhelms-Universität Münster, 4.-5. November 1993

Nr. 28 Kirn, St., Unland, R.: Zur Verbundintelligenz integrierter Mensch-Computer-Teams: Ein organisationstheoretischer Ansatz; März 1994.

Nr. 29 Kirn, St., Unland, R.: Workflow Management mit kooperativen Softwaresystemen: State of the Art und Problemabriß; März 1994.

Nr. 30 Unland, R.: Optimistic Concurrency Control Revisited; März 1994.

Nr. 31 Unland, R.: Semantics-Based Locking: From Isolation to Cooperation; März 1994.

Nr. 32 Meckenstock, A., Unland, R., Zimmer, D.: Controlling Cooperation and Recovery in Nested Transactions; März 1994.

Nr. 33 Kurbel, K., Schnieder, T.: Integration Issues of Information Engineering Based I-CASE Tools; September 1994.

Nr. 34 Unland, R.: TOPAZ: A Tool Kit for the Construction of Application Specific Transaction; November 1994.

Nr. 35 Unland, R.: Organizational Intelligence and Negotiation Based DAI Systems - Theoretical Foundations and Experimental Results; November 1994.

Nr. 36 Unland, R., Kirn, St., Wanka, U., O'Hare, G.M.P., Abbas, S.: AEGIS: AGENT ORIENTED ORGANISATIONS; Februar 1995.

Nr. 37 Jung, R., Rimpler, A., Schnieder, T., Teubner, A.: Eine empirische Untersuchung von Kosteneinflußfaktoren bei integrationsorientierten Reengineering-Projekten; März 1995.

Nr. 38 Kirn, St.: Organisatorische Flexibilität durch Workflow-Management-Systeme?; Juli 1995.

Nr. 39 Kirn, St.: Cooperative Knowledge Processing: The Key Technology for Future Organizations; Juli 1995. 